\title{
A comparative cohort study of totally laparoscopic and open aortobifemoral bypass for the treatment of advanced atherosclerosis
}

This article was published in the following Dove Press journal:

Vascular Health and Risk Management

18 September 2015

Number of times this article has been viewed

\author{
Syed SH Kazmi' \\ Jørgen Junkichi Jørgensen ${ }^{1,2}$ \\ Jon Otto Sundhagen' \\ Anne Helene Krog ${ }^{1,2}$ \\ Tor L Flørenes' \\ Dagfinn Kollerøs ${ }^{3}$ \\ Michael Abdelnoor $2,4,5$ \\ 'Department of Vascular Surgery, \\ Heart, Lung and Vascular Disease \\ Clinic, Oslo University Hospital, \\ ${ }^{2}$ Faculty of Medicine, Oslo University, \\ ${ }^{3}$ Department of Anaesthesiology, \\ Oslo University Hospital, ${ }^{4}$ Unit of \\ Epidemiology and Biological Statistics, \\ ${ }^{5}$ Centre for Clinical Heart Research, \\ Faculty of Medicine, Oslo University, \\ Oslo, Norway
}

Background: Totally laparoscopic aortobifemoral bypass (LABF) procedure has been shown to be feasible for the treatment of advanced aortoiliac occlusive disease (AIOD). This study compares the LABF with the open aortobifemoral bypass (OABF) operation.

Methods: In this prospective comparative cohort study, 50 consecutive patients with type D atherosclerotic lesions in the aortoiliac segment were treated with an LABF operation. The group was compared with 30 patients who were operated on with the OABF procedure for the same disease and time period. We had an explanatory strategy, and our research hypothesis was to compare the two surgical procedures based on a composite event (all-cause mortality, graft occlusion, and systemic morbidity). Stratification analysis was performed by using the Mantel-Haenszel method with the patient-time model. Cox multivariate regression method was used to adjust for confounding effect after considering the proportional hazard assumption. Cox proportional cause-specific hazard regression model was used for competing risk endpoint.

Results: There was a higher frequency of comorbidity in the OABF group. A significant reduction of composite event, $82 \%$ (hazard ratio 0.18 ; 95\% CI $0.08-0.42, P=0.0001$ ) was found in the LABF group when compared with OABF group, during a median follow-up time period of 4.12 years (range from 1 day to 9.32 years). In addition, less operative bleeding and shorter length of hospital stay were observed in the LABF group when compared with the OABF group. All components of the composite event showed the same positive effect in favor of LABF procedure.

Conclusion: LABF for the treatment of AIOD, Trans-Atlantic Inter-Society Consensus II type D lesions, seems to result in a less composite event when compared with the OABF procedure. To conclude, our results need to be replicated by a randomized clinical trial.

Keywords: aortic surgery, laparoscopy, atherosclerosis, aortoiliac atherosclerosis, aortobifemoral bypass, competing risk analysis, minimally invasive surgery

\section{Background}

The main goal of laparoscopic abdominal aortic surgery is not only to provide long-term graft patency and limb salvage rate equivalent to an open abdominal aortic surgery, but also provide the advantages of a minimally invasive procedure. ${ }^{1-4}$ Numbers of laparoscopic aortic procedures, vascular surgeons, and vascular centers performing laparoscopic aortic surgery are steadily increasing. ${ }^{3,5}$

Despite technical advancement and experience within the endovascular procedures, the long-term results of aortobifemoral bypass (ABFB) for the treatment of advanced atherosclerotic lesions in the aortoiliac segment still remain superior. ${ }^{6-9}$ Trans-Atlantic Inter-Society Consensus (TASC) II recommends open surgery as the primary treatment for type D lesions (TASC II). ${ }^{10}$ 
Since the last decade, time and again, the feasibility of the totally laparoscopic aortobifemoral bypass (LABF) procedure has been proven. ${ }^{1-4,11}$ In this article, we present our experience with the LABF operation for the treatment of advanced aortoiliac occlusive disease (AIOD) and TASC II type D lesions. We also present the comparative results between $\mathrm{LABF}$ and open aortobifemoral bypass (OABF) for the treatment of the same disease.

\section{Methods}

The study was approved by the Regional Committees for Medical and Health Research Ethics of Oslo University and also registered at ClinicalTrials.gov (NCT01259908). Informed written consent was obtained from all patients before operation.

This is a prospective and a comparative cohort study with analysis of different outcomes after LABF and OABF (Figure 1). Eighty consecutive patients with TASC II type D lesions were operated with ABFB at the Oslo University Hospital, Aker, Norway, between November 2005 and December 2011. The closing date of the study was on May 15, 2015. Fifty patients underwent LABF and the rest OABF. Table 1 summarizes the clinical characteristics of the patients in the two arms of the cohort.

The major endpoint was the composite event, defined as the first event of a combined incidence of all-cause mortality, graft thrombosis, and systemic morbidity. Systemic morbidity was defined as non-fatal damage or disease with an impact on health that is related to the procedure and involves any organ or tissue other than the peripheral arterial system or surgical wound. ${ }^{12}$ Mortality and graft thrombosis were excluded from this definition. Whereas, the secondary endpoints such as operation time, operative bleeding, and total hospital stay were considered.

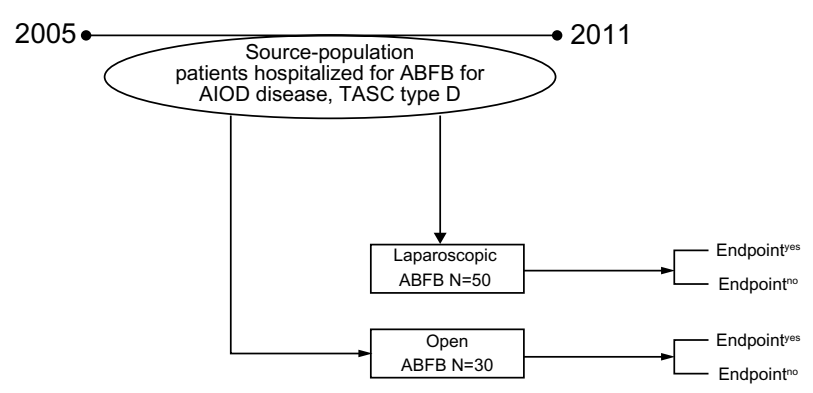

Figure I Flow chart of the comparative cohort study. Laparoscopic aortobifemoral bypass versus open aortobifemoral bypass during the period 2005-20II.

Abbreviations: ABFB, aortobifemoral bypass; AIOD, aortoiliac occlusive disease; TASC, Trans-Atlantic Inter-Society Consensus.
The atherosclerotic lesion in the aortoiliac segment was classified according to the TASC II. ${ }^{10}$ Patients with TASC II type D lesions, not amenable to or with a previously unsuccessful endovascular treatment, were only chosen for surgery. The patients were preoperatively investigated with magnetic resonance angiography. Computed tomography was performed to assess the extent of aortic calcification as well as to identify retroaortic localization of the left renal vein.

The main indication for surgery was debilitating intermittent claudication in all patients, defined as a maximum painfree walking distance of $<200 \mathrm{~m}$ (Rutherford's category 3 ). ${ }^{12}$ Two patients in the LABF and five patients in the OABF group also had rest pain and/or concomitant ischemic wound (Rutherford's category 4 and 5).

Patients with previous multiple major abdominal surgery were not offered laparoscopic surgery $(n=3)$, they underwent open surgery. However, previous appendectomy, cholecystectomy, gastrectomy, or surgery in the pelvic region was not considered a contraindication for a totally laparoscopic procedure. The operation-related variables were compared in the two arms of the cohort.

\section{Epidemiological design and statistical methods}

We had an explanatory strategy, and our research hypothesis was to compare the two surgical procedures. Survival freedom from composite event as well as for the individual components, namely mortality, graft thrombosis, and systemic mortality was presented. Comparison of survival curves was done with the help of the log-rank test. ${ }^{13}$

Stratification analysis was performed by using the MantelHaenszel method with the patient-time model to quantify the confounders and to detect the effect modifiers. ${ }^{14}$

For the primary endpoint and its components, adjusted effect was obtained by using Cox regression model with a manual backward elimination procedure. The adequacy of the proportional hazard was checked with the test of scaled Schoenfeld residuals. A test of interaction using the log likelihood ratio was done when using the Cox model. ${ }^{15}$

Mortality was considered as a competing risk variable for the outcomes, graft thrombosis, and systemic complications. Being an explanatory strategy, cause-specific regression model for hazard function need to be used, for competing risk endpoint instead of the Fine and Gray regression model. ${ }^{16}$

Linear regression model was utilized to control the confounding effect for the secondary continuous outcomes. Stata 13.1 was used for the statistical analysis. 
Table I Clinical characteristics of the patients operated either with totally laparoscopic aortobifemoral bypass (LABF) or with open aortobifemoral bypass (OABF) during the period 2005-201 I

\begin{tabular}{llll}
\hline Variables & LABF, N=50 & OABF, N=30 & Two-tailed P-value \\
\hline Age in years & $62(59-67)^{\mathrm{a}}$ & $62(60-70)^{\mathrm{a}}$ & 0.47 \\
BMI & $24.2(22.8-25.7)^{\mathrm{a}}$ & $25.4(22.4-27.5)^{\mathrm{a}}$ & 0.25 \\
Hypertension & $38(76 \%)$ & $23(77 \%)$ & 0.94 \\
CHD & $17(34 \%)$ & $7(23 \%)$ & 0.31 \\
Dyslipidemia & $30(60 \%)$ & $21(70 \%)$ & 0.36 \\
Diabetes mellitus & $6(12 \%)$ & $8(27 \%)$ & 0.09 \\
Tobacco use & $37(74 \%)$ & $21(70 \%)$ & 0.69 \\
ASA 3 & $36(72 \%)$ & $16(53 \%)$ & 0.09 \\
COPD & $14(28 \%)$ & $4(13 \%)$ & 0.12 \\
Prior vascular intervention/operation & $22(44 \%)$ & $12(40 \%)$ & 0.58 \\
Run-off artery stenosis/occlusion & $21(42 \%)$ & $11(37 \%)$ & 0.63 \\
Suprarenal cross-clamping & 0 & $9(30 \%)$ & 0.001 \\
Prior laparotomy & $14(28 \%)$ & $7(23 \%)$ & 0.64 \\
\hline
\end{tabular}

Notes: aedian and interquartile range.

Abbreviations: ASA 3, The American Society of Anesthesiologists category 3; BMI, body mass index; CHD, coronary heart disease; COPD, chronic obstructive pulmonary disease.

\section{Results}

\section{Composite endpoint and its components}

Survival freedom from composite event showed a 5-year survival of 79.4\% (SE 5.85\%) for LABF versus 37.5\% (SE 9.3\%) for OABF, and a significant difference $(P=0.00001)$ for the log-rank test (Figure 2). The survival freedom from the individual components of the composite endpoint showed a better survival result for LABF when compared with OABF with a significant log-rank test, except for graft thrombosis (Figure 2 and Table 2).

\section{Adjusted effect}

The median follow-up time was 4.12 years (range from 1 day to 9.3 years). Table 3 presents the crude as well as the adjusted effect of operation type on the composite endpoint as well as on the individual components of the composite endpoint. Adjusted Cox's model for the composite endpoint was hazard ratio of 0.18 (95\% CI $0.08-0.42 ; P=0.0001)$, when controlling for age and suprarenal cross-clamping (Table 3). This indicates an $82 \%$ relative reduction of composite events in the laparoscopic procedure group when compared with the open surgery, for a median follow-up time of 4.12 years.

Another analysis was done on different components of composite endpoint controlling for the different confounders. The beneficial effect of LABF was detected on all of the individual components with borderline significance for the incidence of graft thrombosis (due to limited power) (Table 3).

\section{Secondary endpoints}

Median operation time was 265 minutes versus 214 minutes, in LABF and OABF, respectively $(P=0.003)$. The median aorta clamping time was 59.5 minutes versus 36.5 minutes, in the $\mathrm{LABF}$ and $\mathrm{OABF}$, respectively $(P=0.001)$. The aortic clamping time was defined as the time taken to construct the proximal anastomosis. The results of operation-related data in the two groups are presented in Table 2.

The patients in the LABF group had a significantly less operative bleeding $(P=0.0001)$, when compared with the OABF (Table 2). LABF was totally laparoscopic in $43(86 \%)$ patients. All patients received an end-to-side, proximal anastomosis, except in two cases where, due to small aortic aneurysms, an end-to-end anastomosis was performed. Conversion to laparotomy and consequently, open ABFB was done in seven (14\%) patients. Of these, six conversions were among the first half of laparoscopic cohort. Heavily calcified infrarenal aorta $(n=3)$, uncontrolled bleeding from a left retroaortic renal vein $(n=1)$, and failure of the technical instrument $(\mathrm{n}=2)$ were the reasons for conversion to laparotomy. All patients in the OABF group $(n=30)$ underwent median laparotomy, and the infrarenal aorta was approached by free dissecting the peritoneum just to the left side of duodenum. In case of suprarenal cross-clamping (nine cases), pre-aortic left renal vein was mobilized and aorta was cross-clamped just superior to the renal arteries. The median suprarenal crossclamping time was 1 minute (range 1-3 minutes). After the removal of the atherosclerotic plaque, the suprarenal clamp 

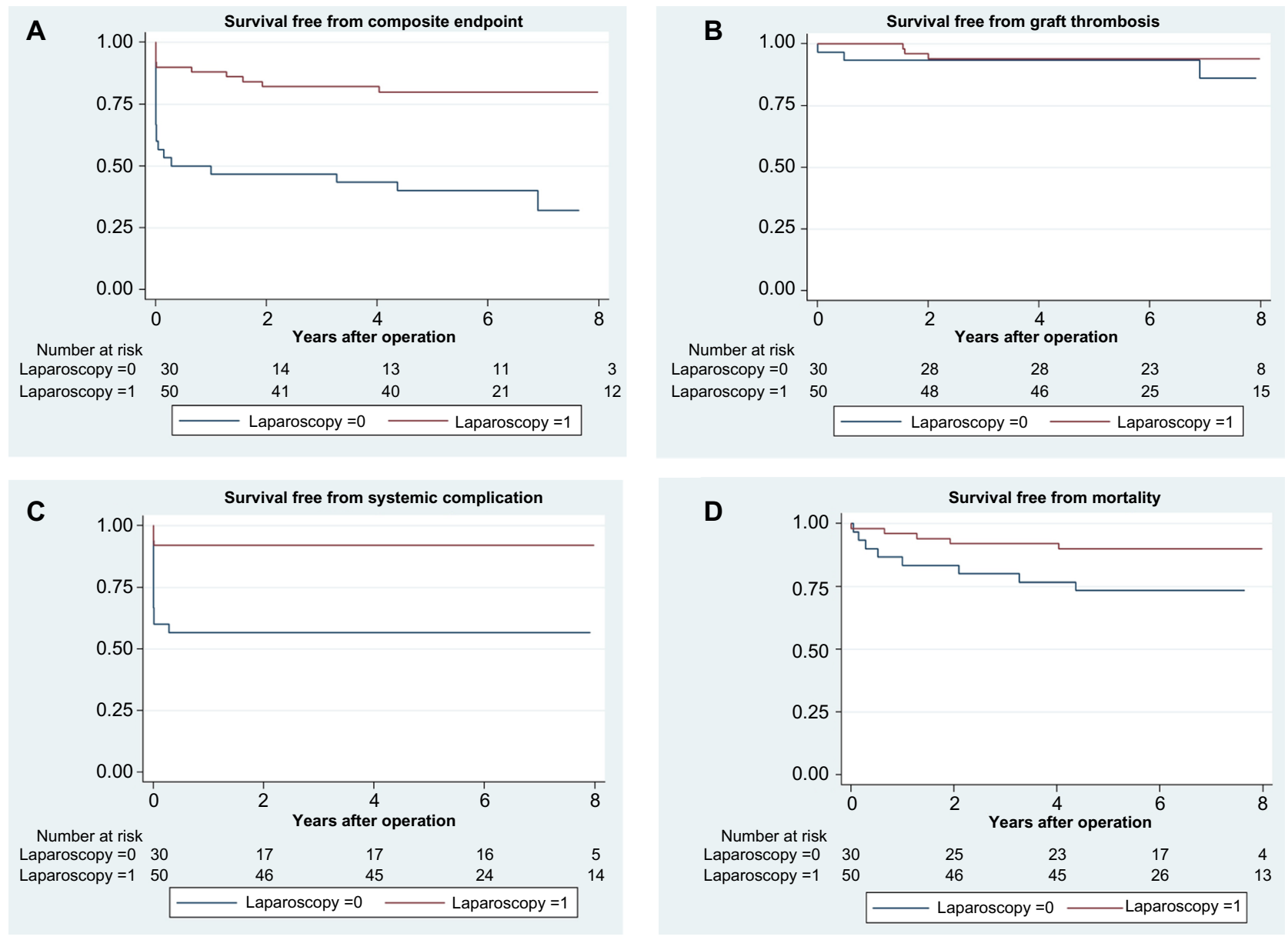

Figure 2 Survival analysis.

Notes: (A) Survival freedom from composite event in the 80 patients' cohort, operated with totally laparoscopic aortobifemoral bypass ( $\mathrm{n}=50$ ) and open aortobifemoral bypass ( $n=30$ ). Median follow-up time period of 4.12 years (range from I day to 9.3 years). (A) Composite event. (B) Graft thrombosis. (C) Systemic complications. (D) Mortality.

was replaced with an infrarenal cross-clamp before aortic anastomosis.

Most of the patients in the LABF were mobilized, and normal food intake could be initiated a day after surgery. Intensive ward stay and hospital stay were significantly shorter for the patients operated with the laparoscopic technique, 5 versus 11 days $(P=0.0002)$ (Figure $2 \mathrm{~A}$ ).

\section{Discussion}

In this study, the results showed $82 \%$ relative reduction of the composite event (all-cause mortality, graft occlusion, and systemic morbidity) in the patients operated with LABF when compared with the $\mathrm{OABF}$ procedure during a median follow-up time period of 4.12 years. This reduction has a relatively huge impact and a clear tendency recommending LABF for the treatment of AIOD.

According to a document released by the Committee for Proprietary Medicinal Products under The European Agency for the Evaluation of Medicinal Products, the use of a composite endpoint in clinical research is usually justified, if the following assumptions are respected:

1. The individual components of the composite endpoint are clinically meaningful and of similar importance to the patient.

2. The expected effects on each component are similar, based on the biological plausibility.

3. The clinically more important components of composite endpoint should at least not be affected negatively.

Consequently, the regulatory authorities will analyze separately all components of a composite endpoint. One needs to be aware whether a treatment affects all components or just a single outcome. ${ }^{17}$

We used the composite endpoint as our primary endpoint, because the cohort is small, and the composite endpoint increases the statistical precision as well as the efficiency of the analysis. ${ }^{18}$ We chose the outcomes, which were only clinically meaningful and of similar importance to the patient. As there can be a competing risk between the individual 
Table 2 Effect of procedure on composite outcome and its components, using the patient-time model

\begin{tabular}{|c|c|c|c|c|}
\hline Endpoint & $\begin{array}{l}\text { LABF, } \mathrm{N}=50 \\
\text { (patient years) }\end{array}$ & $\begin{array}{l}\text { OABF, } N=30 \\
\text { (patient years) }\end{array}$ & $\begin{array}{l}\text { RR ( } 95 \% \text { confidence } \\
\text { interval) }\end{array}$ & $\begin{array}{l}\text { Two-tailed } \\
\text { P-value }\end{array}$ \\
\hline \multicolumn{5}{|l|}{ Major outcome } \\
\hline Mortality & $5(300)$ & $8(160)$ & $0.33(0.08-1.15)$ & 0.005 \\
\hline Graft thrombosis & $3(308)$ & $4(197.8)$ & $0.48(0.07-2.84)$ & 0.051 \\
\hline Systemic complication & $4(295.8)$ & $13(123.5)$ & $0.13(0.03-0.41)$ & 0.00001 \\
\hline $\begin{array}{l}\text { Composite endpoint (mortality, graft } \\
\text { thrombosis, and systemic complication) }\end{array}$ & $10(267)$ & $19(93.5)$ & $0.18(0.07-0.42)$ & 0.00001 \\
\hline \multicolumn{5}{|l|}{ Secondary outcome } \\
\hline Operation time (minutes) & $265(250-291)$ & $214(183-252)$ & & 0.0003 \\
\hline Aorta cross-clamping time (minutes) & $59.5(5 I-76)$ & $26.5(30-95)$ & & 0.0001 \\
\hline Operative bleeding (mL) & $400(300-600)$ & $1000(600-1500)$ & & 0.0001 \\
\hline Hospital stay (days) & $5(4-7)$ & II (8-13) & & 0.0002 \\
\hline
\end{tabular}

Note: Comparison of secondary endpoints between the total laparoscopic aortobifemoral bypass (LABF) or open aortobifemoral bypass (OABF).

Abbreviation: RR, rate ratio.

components of the composite endpoint, so we performed the competing risk analysis and found that graft thrombosis and the systemic complications also individually have the same effect as the composite endpoint in favor of LABF. This confirms the validity of the individual components of the composite endpoint. As studying non-fatal events without including death is methodologically invalid, we included mortality as the third component of composite endpoint in our study.$^{19}$ Figure 2B-D illustrates the survival freedom from the individual components of the composite endpoint.

A substantial amount of evidence about the feasibility of LABF procedure for the treatment of AIOD has been presented since the introduction of this relatively minimally invasive procedure. ${ }^{1-3,11,20}$ However, the general acceptance and the adoption of the laparoscopic procedure by the vascular surgeons have been very poor. A general conception

Table 3 Crude effect of laparoscopic aortobifemoral bypass versus open aortobifemoral bypass

\begin{tabular}{|c|c|c|c|}
\hline Event & Effect & $\begin{array}{l}\text { HR ( } 95 \% \text { confidence } \\
\text { interval) }\end{array}$ & $P$-value \\
\hline \multirow[t]{2}{*}{ Composite endpoint ${ }^{\mathrm{a}}$} & Crude & $0.21(0.09-0.46)$ & 0.0001 \\
\hline & Adjusted $^{c}$ & $0.18(0.08-0.42)$ & 0.0001 \\
\hline \multirow[t]{2}{*}{ Mortality } & Crude & $0.34(0.11-1.04)$ & 0.06 \\
\hline & Adjusted $^{d}$ & $0.27(0.08-0.49)$ & 0.03 \\
\hline \multirow[t]{2}{*}{ Graft thrombosis ${ }^{b}$} & Crude & $0.44(0.10-1.91)$ & 0.27 \\
\hline & Adjusted $^{\mathrm{e}}$ & $0.26(0.06-1.09)$ & 0.06 \\
\hline \multirow[t]{2}{*}{ Systemic complications ${ }^{\mathrm{b}}$} & Crude & $0.15(0.05-0.46)$ & 0.001 \\
\hline & Adjusted $^{f}$ & $0.14(0.04-0.45)$ & 0.001 \\
\hline
\end{tabular}

Notes: ${ }^{\mathrm{C} C o x}$ 's model for composite event and mortality; ${ }^{\mathrm{b}} \mathrm{Cox}$ proportional hazard model for cause-specific hazard for competing risk endpoints, graft thrombosis, and systemic complications; 'adjusted hazard ratio (HR) controlling for age and suprarenal cross-clamping (confounding effect 14.3\%); dadjusted HR for age and suprarenal cross-clamping (confounding effect 20.6\%); eadjusted HR controlling for age and suprarenal cross-clamping (confounding effect $41 \%$ ); ' adjusted HR controlling for sex, ASA classification, BMI, and diabetes mellitus (confounding effect 7\%), using the Cox proportional hazard model.

Abbreviations: ASA, The American Society of Anesthesiologists; BMI, body mass index. about the LABF, as a technically demanding procedure and a fear of inducing complications during the period of learning curve, might have been a reason for the delayed propagation of LABF procedure. ${ }^{3,21}$ However, it is a fact that none of the published series has indicated more complications with LABF when compared with the OABF procedure. ${ }^{1-5}$ Besides, one has to take into account the retrospective nature of many of the earlier results of the OABF procedure. ${ }^{22}$

Fourneau et $\mathrm{a}^{23}$ have shown that the learning curve for the LABF procedures is approximately 25 operations. Our main challenge was that very few patients with the TASC II type D lesions were suitable for surgery.

Although we had three of the total seven conversions due to the aortic calcification, we do not consider circumferential aortic wall calcification as a contraindication to the LABF procedure, as long as it is possible to achieve the suprarenal aortic cross-clamping. ${ }^{2}$ Besides, conversion to laparotomy is not considered as a failure of operative treatment. ${ }^{24}$

Operation time and aortic cross-clamping time, in accordance with the other published series, are longer in the LABF procedure, but they have no significant confounding effect on the mortality and morbidity. ${ }^{1-5}$ Shorter intensive post-stay, early mobilization, and discharge from the hospital advocate for LABF bypass as a procedure of choice for the patients with TASC II type D lesions.

Recently, a very first study of the direct comparison of LABF with the OABF for the treatment of AIOD was published. ${ }^{5}$ Although the study shows less bleeding, shorter hospital stay, and fewer complications in the laparoscopic procedure, it does not define primary and secondary endpoints. Besides, the variability of observation time and the confounding effects of different variables in the two procedures have not been analyzed. Only one randomized controlled trial comparing the $\mathrm{LABF}$ and $\mathrm{OABF}$ has been published, 
but, unfortunately, it was abandoned prematurely, and hence it lacks statistical power to properly address the matters of morbidity and mortality. ${ }^{25}$ There is a need for comparative cohort studies and especially, potential randomized controlled trials to conclusively answer the questions.

Published results of LABF and our own findings in this study may confirm that the LABF has become a standard procedure for the treatment of advanced AIOD in the dedicated institutes. ${ }^{26}$ The main goal of the laparoscopic aortic surgery in future studies should be reviewed, and it should rather be an achievement of less mortality and morbidity when compared with open surgery.

\section{Conclusion}

Totally LABF for the treatment of AIOD, TASC II type D lesions, seems to result in less composite event when compared with open surgery. To conclude, our results need to be replicated by a randomized clinical trial.

\section{Acknowledgments}

We are extremely thankful for the kind assistance of Dr Marc Coggia, in guiding and providing his expert assistance for the initial LABF procedures in this study. We are also extremely thankful for the constructive criticisms and a continuous support of our colleagues at the Department of Vascular Surgery, Oslo University Hospital, Oslo, Norway as well as the nursing staff at the surgical section.

\section{Author contributions}

SSHK contributed to conception and design; all authors collected data; SSHK and MA analyzed and interpreted the data, and performed statistical analysis; all authors drafted and critically reviewed the article; SSHK, MA, and JJJ approved the final version of the article; SSHK held the overall responsibility for this study. All authors have approved the final version.

\section{Disclosure}

The authors report no conflicts of interest in this work.

\section{References}

1. Dion YM, Griselli F, Douville Y, Langis P. Early and mid-term results of totally laparoscopic surgery for aortoiliac disease: lessons learned. Surg Laparosc Endosc Percutan Tech. 2004;14(6):328-334.

2. Coggia M, Javerliat I, Di Centa I, et al. Total laparoscopic bypass for aortoiliac occlusive lesions: 93-case experience. J Vasc Surg. 2004;40(5):899-906.

3. Cau J, Ricco JB, Corpataux JM. Laparoscopic aortic surgery: techniques and results. J Vasc Surg. 2008;48(6 Suppl):37S-44S; discussion 5S.

4. Kazmi SSH, Sundhagen JO, Flørenes TL, Kroese AJ, Jørgensen JJ. Laparoskopisk aortakirurgi. Tidsskr Nor Lageforen. 2007;127(11): 1518-1520.
5. Bruls S, Quaniers J, Tromme P, et al. Comparison of laparoscopic and open aortobifemoral bypass in the treatment of aortoiliac disease. Results of a contemporary series (2003-2009). Acta Chir Belg. 2012; 112(1):51-58.

6. Kashyap VS, Pavkov ML, Bena JF, et al. The management of severe aortoiliac occlusive disease: endovascular therapy rivals open reconstruction. J Vasc Surg. 2008;48(6):1451-1457, 1457.e1-e3.

7. Tsetis D, Uberoi R. Quality improvement guidelines for endovascular treatment of iliac artery occlusive disease. Cardiovasc Intervent Radiol. 2008;31(2):238-245.

8. Pulli R, Dorigo W, Fargion A, et al. Early and long-term comparison of endovascular treatment of iliac artery occlusions and stenosis. JVasc Surg. 2011;53(1):92-98.

9. Kim TH, Ko YG, Kim U, et al. Outcomes of endovascular treatment of chronic total occlusion of the infrarenal aorta. JVasc Surg. 2011;53(6): $1542-1549$.

10. Norgren L, Hiatt WR, Dormandy JA, Nehler MR, Harris KA, Fowkes FG. Inter-society consensus for the management of peripheral arterial disease (TASC II). J Vasc Surg. 2007;45(Suppl S):S5-S67.

11. Kolvenbach R, Puerschel A, Fajer S, et al. Total laparoscopic aortic surgery versus minimal access techniques: review of more than 600 patients. Vascular. 2006;14(4):186-192.

12. Rutherford RB, Baker JD, Ernst C, et al. Recommended standards for reports dealing with lower extremity ischemia: revised version. $J$ Vasc Surg. 1997;26(3):517-538.

13. Kleinbaum DG, Klein M. Survival Analysis: A Self-learning Text. 3rd ed. New York: Springer; 2011.

14. Kleinbaum DG, Kupper LL, Morgenstern H. Epidemiologic Research: Principles and Quantitative Methods. New York: John Wiley and Sons; 1982.

15. Kirkwood BR. Essentials of Medical Statistics. Carlton, VIC: Blackwell Science Ltd; 2003.

16. Wolbers M, Koller MT, Stel VS, et al. Competing risks analysis: objectives and approaches. Eur Heart J. 2014;35(42):2936-2941.

17. Committee for Proprietary Medicinal Products (CPMP). "Points to Consider on Multiplicity Issues in Clinical Trials," London: The European Agency for the Evaluation of Medicinal Products. Available from http:// www.ema.europa.eu/docs/en_GB/document_library/Scientific_guideline/2009/09/WC500003640.pdf. Accessed July 1, 2015.

18. Freemantle N, Calvert M, Wood J, Eastaugh J, Griffin C. Composite outcomes in randomized trials: greater precision but with greater uncertainty? J Am Med Assoc. 2003;289(19):2554-2559.

19. Skali H, Solomon SD, Pfeffer MA. Are we asking too much of our trials? Am Heart J. 2002;143(1):1-3.

20. Nio D, Diks J, Bemelman WA, Wisselink W, Legemate DA. Laparoscopic vascular surgery: a systematic review. Eur J Vasc Endovasc Surg. 2007;33(3):263-271.

21. Alimi YS, Mouret F, Garitey V, Rieu R. Laparoscopic aortic surgery: recent development in instrumentation. Surg Technol Int. 2005;14: 253-261.

22. de Vries SO, Hunink MG. Results of aortic bifurcation grafts for aortoiliac occlusive disease: a meta-analysis. J Vasc Surg. 1997;26(4): 558-569.

23. Fourneau I, Lerut P, Sabbe T, Houthoofd S, Daenens K, Nevelsteen A. The learning curve of totally laparoscopic aortobifemoral bypass for occlusive disease. How many cases and how safe? Eur JVasc Endovasc Surg. 2008;35(6):723-729.

24. Fourneau I, Marien I, Remy P, et al. Conversion during laparoscopic aortobifemoral bypass: a failure? Eur JVasc Endovasc Surg. 2010;39(2): 239-245.

25. Tiek J, Remy P, Sabbe T, et al. Laparoscopic versus open approach for aortobifemoral bypass for severe aorto-iliac occlusive disease - a multicentre randomised controlled trial. Eur J Vasc Endovasc Surg. 2012;43(6):711-715.

26. McKinlay JB. From "promising report" to "standard procedure": seven stages in the career of a medical innovation. Milbank Mem Fund $Q$ Health Soc. 1981;59(3):374-411. 
Vascular Health and Risk Management

Dovepress

\section{Publish your work in this journal}

Vascular Health and Risk Management is an international, peerreviewed journal of therapeutics and risk management, focusing on concise rapid reporting of clinical studies on the processes involved in the maintenance of vascular health; the monitoring, prevention and treatment of vascular disease and its sequelae; and the involvement of metabolic disorders, particularly diabetes. This journal is indexed on PubMed Central and MedLine. The manuscript management system is completely online and includes a very quick and fair peer-review system, which is all easy to use. Visit http://www.dovepress.com/ testimonials.php to read real quotes from published authors.

Submit your manuscript here: http://www.dovepress.com/vascular-health-and-risk-management-journal 